\title{
High Work Output Combined With High Ambient Temperatures Caused Heat Exhaustion in a Wildland Firefighter Despite High Fluid Intake
}

\author{
John S. Cuddy, MS; Brent C. Ruby, PhD \\ From the Montana Center for Work Physiology and Exercise Metabolism, The University of Montana, Missoula, MT (Mr Cuddy and Dr \\ Ruby).
}

\begin{abstract}
The purpose of this case study is to examine the physiological/behavioral factors leading up to heat exhaustion in a male wildland firefighter during wildland fire suppression. The participant (24 years old, $173 \mathrm{~cm}, 70 \mathrm{~kg}$, and 3 years firefighting experience) experienced heat exhaustion following 7 hours of high ambient temperatures and arduous work on the fire line during the month of August. At the time of the heat-related incident (HRI), core temperature was $40.1^{\circ} \mathrm{C}\left(104.2^{\circ} \mathrm{F}\right)$ and skin temperature was $34.4^{\circ} \mathrm{C}\left(93.9^{\circ} \mathrm{F}\right)$. His work output averaged 1067 counts $\cdot \mathrm{min}^{-1}$ (arbitrary units for measuring activity) for the 7 hours prior to the HRI, a very high rate of work over an extended time period during wildfire suppression. In the 2.5 hours leading up to the heat incident, he was exposed to a mean ambient temperature of $44.6^{\circ} \mathrm{C}\left(112.3^{\circ} \mathrm{F}\right)$, with a maximum temperature of $59.7^{\circ} \mathrm{C}\left(139.5^{\circ} \mathrm{F}\right)$. He consumed an average of $840 \mathrm{~mL} \cdot \mathrm{h}^{-1}$ in the 7 hours leading up to the incident and took an average of $24 \pm 11$ drinks $\cdot \mathrm{h}^{-1}$ (total of 170 drinks). The combined effects of a high work rate and high ambient temperatures resulted in an elevated core temperature and a higher volume and frequency of drinking than typically seen in this population, ultimately ending in heat exhaustion and removal from the fire line. The data demonstrate that heat-related incidents can occur even with aggressive fluid intake during wildland fire suppression.
\end{abstract}

Key words: fluid intake, wildland firefighters, heat exhaustion

\section{Heat-Related Illness}

Heat-related illnesses can manifest in occupations that demand a high amount of physical work in high ambient temperatures. Heat-related illnesses include heat edema, cramps, syncope, heat exhaustion, and heat stroke. ${ }^{1}$ Symptoms occur when the metabolic heat production from muscle activity and/or heat acquisition from the environment are greater than the ability of the body to dissipate heat. This limits the ability to maintain core body temperature within a safe range, resulting in hyperthermia. While performing strenuous work, the inability to dissipate body heat can result from a multitude of factors, including lack of environmental acclimatization, poor physical fitness, dehydration, medications, drugs,

Corresponding author: Brent C. Ruby, PhD, Director, Montana Center for Work Physiology and Exercise Metabolism, Department of Health and Human Performance, The University of Montana, McGill Hall - HHP, Missoula, MT 59812-1825 (e-mail: brent.ruby@ mso.umt. edu). supplements, high body mass, specific genotypes, muscle injury, and illness. ${ }^{2,3}$ The purpose of this case study is to examine the physiological/behavioral factors leading up to a heat-related incident (HRI) during wildland fire suppression.

\section{Presentation of Case}

In the summer of 2004, during a hydration study, ${ }^{4}$ we captured physiological data from a male wildland firefighter (WLFF) (24 years old, $173 \mathrm{~cm}, 70 \mathrm{~kg}$, and 3 years firefighting experience) who experienced heat exhaustion during a work shift. The participant was in the waterdrinking-only group. In the 2.5 hours leading up to the heat incident, the individual was exposed to a mean ambient temperature of $44.6^{\circ} \mathrm{C}\left(112.3^{\circ} \mathrm{F}\right)$, with a maximum temperature of $59.7^{\circ} \mathrm{C}\left(139.5^{\circ} \mathrm{F}\right)$ (see Figure 1 for pattern of ambient exposure). During this time period, he had 113 minutes $(75 \%)$ of exposure to temperatures 


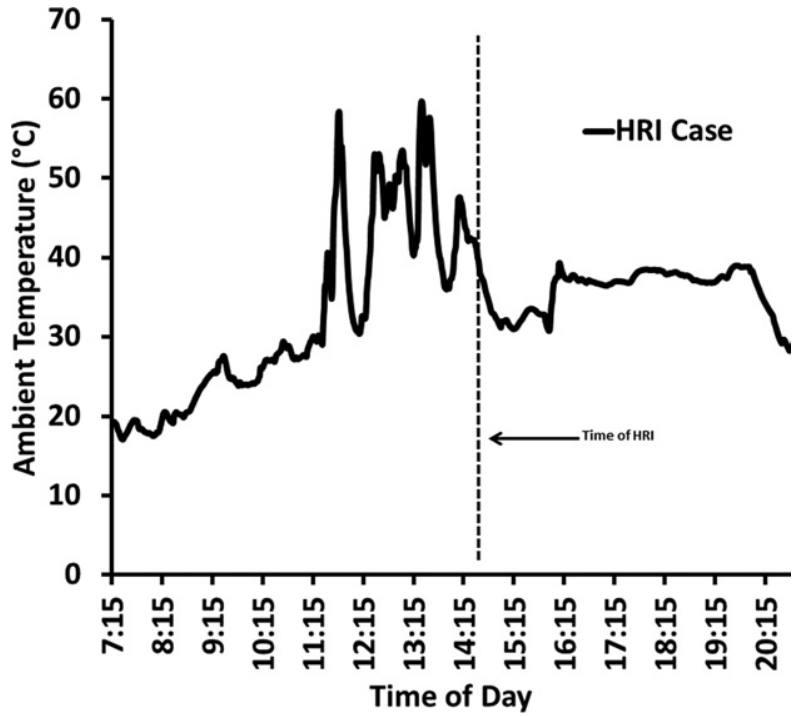

Figure 1. Ambient temperature $\left({ }^{\circ} \mathrm{C}\right)$ during the work shift.

$\geq 40^{\circ} \mathrm{C}\left(104^{\circ} \mathrm{F}\right)$. His work output averaged 1067 counts - $\min ^{-1}$ for 7 hours, a very high rate of work over an extended time period during wildfire suppression (typical work outputs are $300-600$ counts $\cdot \min ^{-1}$ for a day [see Figure 2]). ${ }^{4-6}$ The participant's core temperature reached a maximum of $40.1^{\circ} \mathrm{C}\left(104.2^{\circ} \mathrm{F}\right)$ prior to the incident; the pattern of core temperature leading up to the incident can be seen in Figure 3. Average skin temperature for the 7 hours leading up to the heat injury time point was $33.1^{\circ} \mathrm{C}$ $\left(91.6^{\circ} \mathrm{F}\right)$, whereas at the time of the heat injury, skin temperature was $34.4^{\circ} \mathrm{C}\left(93.9^{\circ} \mathrm{F}\right)$. In response to his high work output and exposure to high temperatures, he drank an average of $840 \mathrm{~mL} \cdot \mathrm{h}^{-1}(5.9 \mathrm{~L})$ in the 7 hours leading

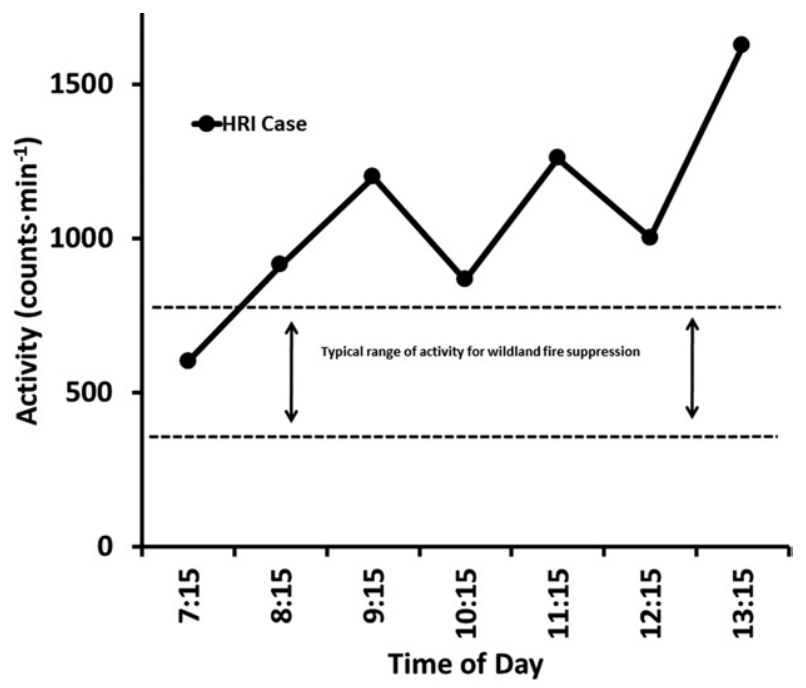

Figure 2. Activity patterns in the 7 hours leading up to the heat incident.

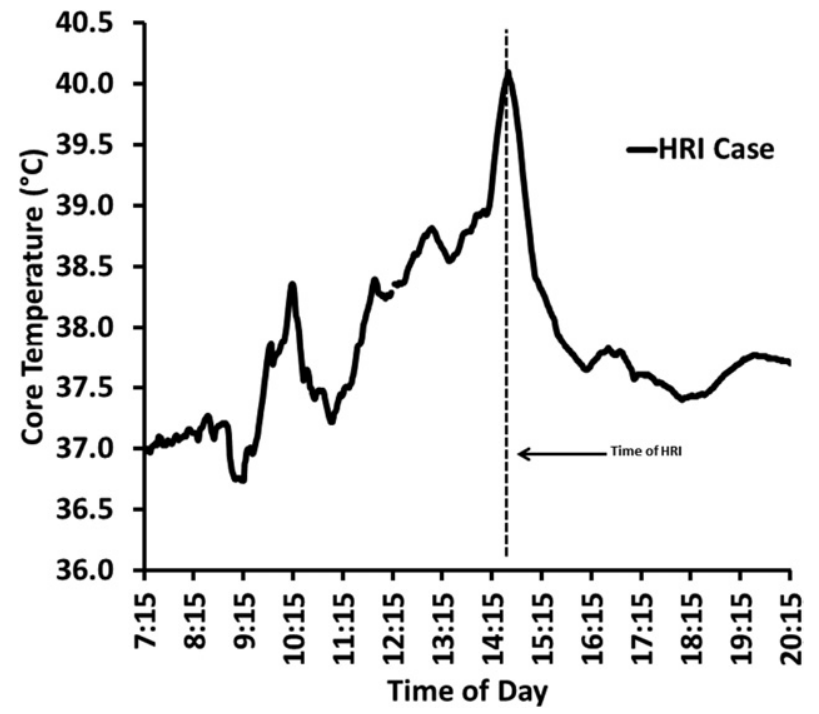

Figure 3. Core temperature $\left({ }^{\circ} \mathrm{C}\right)$ during the work shift for participants and HRI case study subject.

up to the incident. He took an average of $24 \pm 11$ drinks $\cdot \mathrm{h}^{-1}$ over the 7 hours leading up to the heat injury (total of 170 drinks). As a result of his heat exhaustion, he was evacuated from the fire line via helicopter for immediate medical attention, a very rare occurrence in the wildland firefighting community.

\section{Novelty of Case Situation}

The rate of HRIs during work is relatively low. In an 11-year analysis of occupational HRIs in Washington State, Bonauto et al determined third quarter (July, August, and September) workers' compensation time claim rates attributed to HRIs were 158.8 per 100000 FTE $(1$ FTE $=2000$ work hours $)$ for fire protection. ${ }^{1}$ This means, for example, 1 out of every 630 firefighters experienced an HRI during the third quarter that prevented them from attending work. Considering the low incidence rate of HRIs, and the few people tested during the field study $(n=16)$, the odds of capturing data from an HRI (based upon data from Bonauto et al) during the third quarter are minimal (1 in 101385 work days), making this an incredibly rare data set to acquire. Capturing this kind of data in a laboratory setting would likely never occur because preventive measures would be in place to stop a participant before he/she achieved this level of heat stress; thus, the field research model allowed for such a situation to occur.

\section{Physiological Monitors}

Prior to the work shift, the participant ingested a core temperature capsule (Mini Mitter, A Respironics Com- 
pany, Bend, OR) and had a skin temperature sensor (Mini Mitter, A Respironics Company, Bend, OR) placed on the lateral side of the left deltoid. To collect ambient temperature, an additional surface temperature sensor was placed on the outside of the VitalSense monitor holster (Mini Mitter, A Respironics Company, Bend, OR) that was worn on the subject's belt. The participant was provided with a specially outfitted backpack hydration system (3-liter capacity Camelback). The system was equipped with a digital flow-meter system affixed inline to allow for the measurement of drinking characteristics (drinking frequency and drinking volume). ${ }^{7}$ Activity data were collected using the Actical actigraphy units (Mini Mitter, A Respironics Company, Bend, OR) via methods previously described. ${ }^{5}$

\section{Commentary}

Wildland fire suppression is a seasonal occupation that encompasses long work shifts (approximately 16 hours) over 14-day cycles with 2 days of rest in between. For seasonal workers in the western United States, the fire season usually lasts from May to September. We have previously determined that the energy expenditure associated with wildland fire suppression ranges from 12 to $26 \mathrm{MJ} \cdot$ day $^{-1}\left(2868-6214 \mathrm{kCal} \cdot\right.$ day $\left.^{-1}\right) .^{8}$ Additionally, the daily water turnover rates (over 5 days) in WLFFs averaged $6.7 \pm 1.4 \mathrm{~L} \cdot \mathrm{d}^{-1}(94.8 \pm 24.1 \mathrm{~mL}$. $\left.\mathrm{kg}^{-1} \cdot \mathrm{d}^{-1}\right){ }^{9}$ Although these numbers indicate daily work efforts and hydration demands higher than most field occupations, the majority of time spent during wildland fire suppression is sedentary, accounting for approximately 61 to $66 \%$ of work time. ${ }^{5}$ Most of the work activity is at a light intensity with intermittent bouts of moderate and/or vigorous activity. All WLFFs wear standard fire equipment: Nomex long-sleeve shirt and pants, mid-calf leather logger boots, a 100\% cotton short-sleeve undershirt, leather gloves, hard hat, and a 12 to $20 \mathrm{~kg}$ pack containing food, water, safety gear, and work tools. ${ }^{8}$ A report by Missoula Technology and Development Center in Spring 2006 discusses that heat-related injuries are a substantial risk during wildland firefighter training and job performance because of frequent high ambient temperature conditions, elevated work intensity, fatigue, hydration challenges, wearing uniforms/protective gear, and carrying packs. ${ }^{10}$

The combination of an arduous work effort and high ambient conditions are likely the key contributors to this heat episode, and the participant's increased rate of fluid consumption (2.6 times higher than other firefighters working alongside him) did not prevent the rise in core temperature.
In the 7 hours prior to the HRI case study subject's heat injury, his work rate was the highest individual work rate this laboratory has observed with this methodology (data reviewed from 132 individual participants, totaling 321 work days) ${ }^{4-6}$ (and J.S.C., unpublished data, 2005 and 2008). As evidenced by this incident, WLFFs should slow down work rates (if possible) when exposed to high ambient/fire temperatures to mitigate the risk for heat injuries, since metabolic heat dissipation becomes increasingly difficult.

More substantial than the subject's high work rate was his exposure to extreme ambient temperatures over extended duration. In the 2.5 hours leading up to the heat injury, the HRI case spent 113 minutes at temperatures $\geq 40^{\circ} \mathrm{C}\left(104^{\circ} \mathrm{F}\right)$, of which 41 minutes were at temperatures $\geq 50^{\circ} \mathrm{C}\left(122^{\circ} \mathrm{F}\right)$; the average temperature during the 2.5 hours was $44.6^{\circ} \mathrm{C}\left(112.3^{\circ} \mathrm{F}\right)$. The combined effects of accumulating heat from the environment and generating metabolic heat from a high work rate set the stage for compromised thermoregulation. As a result of his arduous work rate and the elevated ambient temperatures, his core temperature exceeded $40^{\circ} \mathrm{C}\left(104^{\circ} \mathrm{F}\right)$, yet he maintained an ample gradient between core and skin in the 2 hours preceding the injury $\left(4.8 \pm 3.8^{\circ} \mathrm{C} ; 9.2 \pm 1.6^{\circ} \mathrm{F}\right)$; thus, he was still able to dissipate heat to the periphery. His skin temperature never exceeded $35^{\circ} \mathrm{C}\left(95^{\circ} \mathrm{F}\right)$ in the 2 hours leading up to his injury. It is difficult to ascertain whether attainment of $40.1^{\circ} \mathrm{C}\left(104.2^{\circ} \mathrm{F}\right)$ was a critical, performance-limiting temperature for this participant. In past literature, exceeding $40^{\circ} \mathrm{C}\left(104^{\circ} \mathrm{F}\right)$ during exercise was considered a "critical" temperature that had potential to limit performance, ${ }^{11,12}$ yet there is recent evidence to challenge this theory as long as skin temperatures remain cool during self-regulated exercise intensities. ${ }^{13}$ To alleviate exposure to very high temperatures when working arduously, a WLFF should periodically withdraw from the heat and find cooler refuge if feeling excessively hot from exposure to high ambient/fire temperatures.

During the work shift, the subject consumed copious amounts of fluid $\left(5.9 \mathrm{~L}, 840 \mathrm{~mL} \cdot \mathrm{h}^{-1}\right)$ over the course of 7 hours. Compared to typical wildfire suppression drinking patterns, this is a very high rate of fluid consumption (mean consumption for other participants in this study was reported at $504 \pm 472$ and $285 \pm 279 \mathrm{~mL} \cdot \mathrm{h}^{-1}$, depending on type of drink consumed). He drank very frequently, taking an average of $24 \pm 11$ drinks $\cdot \mathrm{h}^{-1}$ over the 7 hours leading up the heat injury (total of 170 drinks). The other firefighters working alongside him consumed $9 \pm 6$ drinks $\cdot \mathrm{h}^{-1}$ over the 7 hours leading up to the heat injury, meaning the heat case participant drank 2.6 times more frequently. This may have been a learned drinking-strategy behavior since he was an experienced WLFF, or it was in response to his increasing 
work output and core temperature. Despite his elevated intake of fluids in response to arduous work output and high ambient temperatures, he still suffered heat injury. These data suggest that practices promoting abundant drinking may: 1) not be able to compensate for the heat production/exposure associated with arduous work rates and high ambient environmental temperatures; and/or 2) provide a false sense of protection during periods of arduous work.

Since heat casualties were not part of the project goals, much is unknown regarding this episode outside of fire line evacuation due to heat exhaustion. Nonetheless, the combined effects of a high work rate and high ambient temperatures resulted in an elevated core temperature and a higher volume and frequency of drinking than typically seen in this population, ultimately ending in heat exhaustion and removal from the fire line. The data demonstrate that heat-related incidents can occur even with aggressive fluid intake during wildland fire suppression. Thus, strategies beyond classic hydration recommendations are necessary to alleviate heat injuries in situations that might be life-threatening to the individual or those around the individual if a heat injury occurs.

\section{Acknowledgments}

Research funded by the United States Forest Service (USFS) and Mineral Resources (manufacturers of Elete). The views, opinions, and/or findings contained in this publication are those of the authors and should not be construed as an official United States Forest Service position, policy, or decision unless so designated by other documentation.

\section{References}

1. Bonauto D, Anderson R, Rauser E, Burke B. Occupational heat illness in Washington State, 1995-2005. Am J Ind Med. 2007;50:940-950.
2. DeFranco MJ, Baker CL III, DaSilva JJ, Piasecki DP, Bach BR Jr. Environmental issues for team physicians. Am J Sports Med. 2008;36:2226-2237.

3. Carter R III, Cheuvront SN, Williams JO, et al. Epidemiology of hospitalizations and deaths from heat illness in soldiers. Med Sci Sports Exerc. 2005;37:1338-1344.

4. Cuddy JS, Ham JA, Harger SG, Slivka DR, Ruby BC. Effects of an electrolyte additive on hydration and drinking behavior during wildfire suppression. Wilderness Environ Med. 2008;19:172-180.

5. Cuddy JS, Gaskill SE, Sharkey BJ, Harger SG, Ruby BC. Supplemental feedings increase self-selected work output during wildfire suppression. Med Sci Sports Exerc. 2007; 39:1004-1012.

6. Montain SJ, Baker-Fulco CJ, Niro PJ, Reinert AR, Cuddy JS, Ruby BC. Efficacy of eat-on-move ration for sustaining physical activity, reaction time, and mood. Med Sci Sports Exerc. 2008;40:1970-1976.

7. DeGroot DW, Kesick CM, Stulz RW, Hoyt RW, Lanza JF, Montain SJ. New instrument to measure ad libitum fluid intake in the field. Med Sci Sports Exerc. 2001;33:S257.

8. Ruby BC, Shriver TC, Zderic TW, Sharkey BJ, Burks C, Tysk S. Total energy expenditure during arduous wildfire suppression. Med Sci Sports Exerc. 2002;34:1048-1054.

9. Ruby BC, Schoeller DA, Sharkey BJ, Burks C, Tysk S. Water turnover and changes in body composition during arduous wildfire suppression. Med Sci Sports Exerc. 2003; 35:1760-1765.

10. Sharkey BJ. Wildland firefighter health and safety report: No. 10. Tech. Rep. 0651-2810-MTDC. In: U.S. Department of Agriculture Forest Service MTaDC (ed), 2005:12.

11. Gonzalez-Alonso J, Teller C, Andersen SL, Jensen FB, Hyldig T, Nielsen B. Influence of body temperature on the development of fatigue during prolonged exercise in the heat. J Appl Physiol. 1999;86:1032-1039.

12. Nielsen B, Hales JR, Strange S, Christensen NJ, Warberg J, Saltin B. Human circulatory and thermoregulatory adaptations with heat acclimation and exercise in a hot, dry environment. J Physiol. 1993;460:467-485.

13. Ely BR, Ely MR, Cheuvront SN, Kenefick RW, Degroot DW, Montain SJ. Evidence against a 40 degrees C core temperature threshold for fatigue in humans. $J$ Appl Physiol. 2009;107:1519-1525. 